\title{
Numerical Simulation of Size Effects on Countercurrent Flow Limitation in PWR Hot Leg Models
}

\author{
I. Kinoshita, ${ }^{1,2}$ M. Murase, ${ }^{1}$ and A. Tomiyama ${ }^{2}$ \\ ${ }^{1}$ Institute of Nuclear Technology, Institute of Nuclear Safety System, Inc., 64 Sata, Mihama-cho, \\ Mikata-gun, Fukui 919-1205, Japan \\ ${ }^{2}$ Department of Mechanical Engineering, Graduate School of Engineering, Kobe University, 1-1 Rokkodai, \\ Nada-ku, Kobe 657-8501, Japan \\ Correspondence should be addressed to I. Kinoshita, kinoshita@inss.co.jp
}

Received 10 January 2012; Revised 6 March 2012; Accepted 6 March 2012

Academic Editor: Thomas Hoehne

Copyright ( $) 2012$ I. Kinoshita et al. This is an open access article distributed under the Creative Commons Attribution License, which permits unrestricted use, distribution, and reproduction in any medium, provided the original work is properly cited.

\begin{abstract}
We have previously done numerical simulations using the two-fluid model implemented in the CFD software FLUENT6.3.26 to investigate effects of shape of a flow channel and its size on CCFL (countercurrent flow limitation) characteristics in PWR hot leg models. We confirmed that CCFL characteristics in the hot leg could be well correlated with the Wallis parameters in the diameter range of $0.05 \mathrm{~m} \leq D \leq 0.75 \mathrm{~m}$. In the present study, we did numerical simulations using the two-fluid model for the air-water tests with $D=0.0254 \mathrm{~m}$ to determine why CCFL characteristics for $D=0.0254 \mathrm{~m}$ were severer compared with those in the range, $0.05 \mathrm{~m} \leq D \leq 0.75 \mathrm{~m}$. The predicted CCFL characteristics agreed with the data for $D=0.0254 \mathrm{~m}$ and indicated that the CCFL difference between $D=0.0254 \mathrm{~m}$ and $0.05 \mathrm{~mm} \leq D \leq 0.75 \mathrm{~mm}$ was caused by the size effect and not by other factors.
\end{abstract}

\section{Introduction}

Reflux condensation by steam generators (SGs) is considered as one of the possible core cooling methods under hypothetical accident conditions in pressurized water reactors (PWRs). During the reflux condensation, the water condensed in SG U-tubes has to flow countercurrent to the steam generated in the reactor core. The core cooling performance heavily depends on the occurrence of countercurrent flow limitation (CCFL) in the hot leg which consists of a horizontal pipe, an elbow, and an inclined pipe. As reviewed by Al Issa and MacIan [1], many experiments have been conducted to investigate the CCFL characteristics in the hot leg, and empirical correlations have been proposed using Wallis parameters [2]. The review showed that many differences between CCFL data were simply due to geometrical effects. To compare CCFL characteristics in hot leg models, Vallée et al. [3] selected three geometrical factors: the horizontal pipe length to diameter ratio $\left(L_{H} / D\right)$, the inclined pipe length to diameter ratio $\left(L_{I} / D\right)$, and the elbow angle $\theta$. They showed that even for similar geometrical factors, there was clear deviation between CCFL characteristics due to size effects. In order to evaluate effects of size better, numerical simulation using CFD (computational fluid dynamics) software is expected to be useful.

In order to investigate effects of shape of a flow channel and its size on CCFL characteristics in hot leg models, we have previously done numerical simulations using a two-fluid model implemented in the CFD software FLUENT6.3.26 [4-6]. We found that the two-fluid model could reproduce CCFL characteristics under low-pressure conditions, and we confirmed that those in the hot leg could be well correlated with the Wallis parameters in the region of $0.05 \mathrm{~m} \leq D \leq 0.75 \mathrm{~m}$ [6]. On the other hand, CCFL characteristics for $D=0.0254 \mathrm{~m}$ measured by Ohnuki et al. [7] were severer compared with those in the range $0.05 \mathrm{~m} \leq$ $D \leq 0.75 \mathrm{~m}$.

In this paper, we did numerical simulations using the two-fluid model for the air-water tests $(D=0.0254 \mathrm{~m})$ conducted by Ohnuki et al. [7] to evaluate whether the CCFL difference between $D=0.0254 \mathrm{~m}$ and $0.05 \mathrm{~m} \leq D \leq 0.75 \mathrm{~m}$ is because of the size effect or other factors. 
TABLE 1: Test section dimensions and conditions.

\begin{tabular}{|c|c|c|c|c|c|c|}
\hline Reference & $D(\mathrm{~m})$ & $L_{H} / D(-)$ & $L_{I} / D(-)$ & $\theta(\mathrm{deg})$ & Fluids & Pressure (MPa) \\
\hline Ohnuki et al. [7] & 0.0254 & 9.1 & 1.2 & 50 & Air-water & 0.1 \\
\hline Richter et al. [8] & 0.2032 & 4.5 & 0 & 45 & Air-water & 0.1 \\
\hline Mayinger et al. [9] & 0.750 & 9.0 & 1.1 & 50 & Steam-water & $0.3,1.5$ \\
\hline Geffraye et al. [10] & 0.351 & 7.5 & 3.0 & 50 & Air-water & 0.1 \\
\hline Navarro [11] & 0.054 & 9.3 & 1.9 & 50 & Air-water & 0.1 \\
\hline Minami et al. [12] & 0.050 & 8.4 & 1.2 & 50 & Air-water & 0.1 \\
\hline
\end{tabular}

$D$ : diameter, $L_{H}$ : length of horizontal pipe, $L_{I}$ : length of inclined pipe, $\theta$ : angle of elbow.

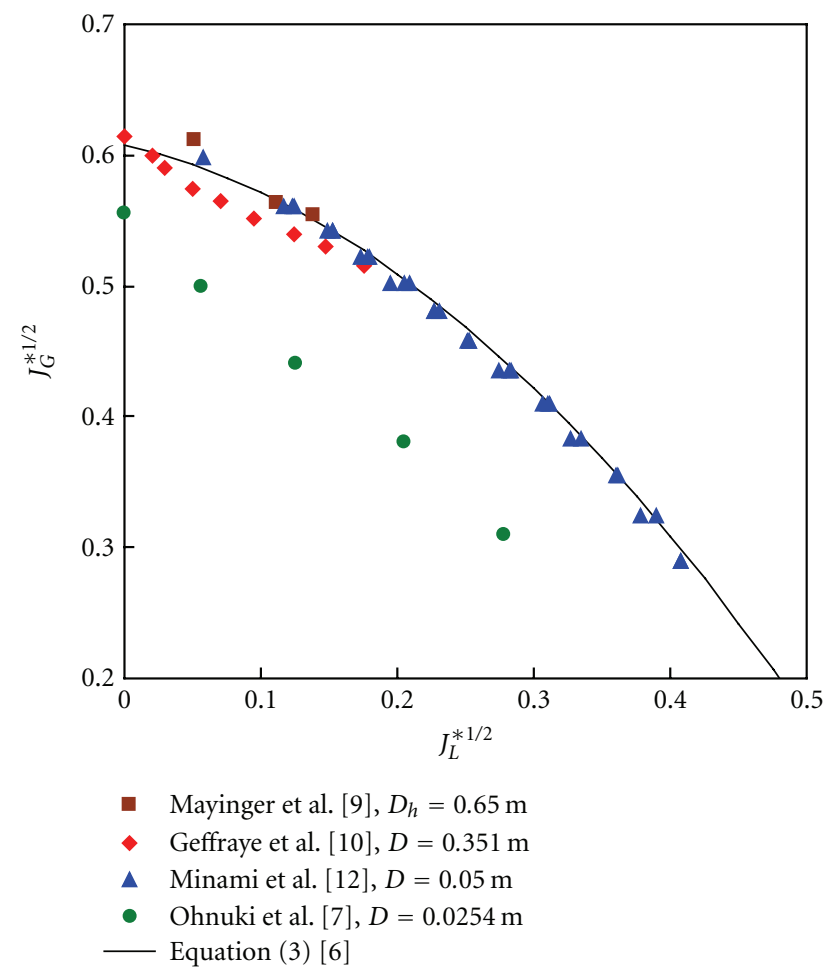

FIGURE 1: CCFL characteristics.

\section{CCFL Characteristics in a Hot Leg Geometry}

CCFL characteristics in a PWR hot leg are generally expressed by using the Wallis correlation or Wallis parameters which are respectively defined by [2]

$$
\begin{gathered}
\left(J_{G}^{*}\right)^{1 / 2}+m\left(J_{L}^{*}\right)^{1 / 2}=C, \\
J_{k}^{*}=J_{k}\left\{\frac{\rho_{k}}{g \cdot \ell \cdot\left(\rho_{L}-\rho_{G}\right)}\right\}^{1 / 2}, \\
\quad \ell=D \text { or } H(k=G \text { or } L),
\end{gathered}
$$

where $J(\mathrm{~m} / \mathrm{s})$ is the volumetric flux in the hot leg, $m$ and $C$ are empirical constants, $\ell(\mathrm{m})$ is the characteristic length, $D(\mathrm{~m})$ is the diameter of the hot leg, $H(\mathrm{~m})$ is the height of a hot leg model with a rectangular channel, $g\left(\mathrm{~m} / \mathrm{s}^{2}\right)$ is the gravity acceleration, and $\rho\left(\mathrm{kg} / \mathrm{m}^{3}\right)$ is the density.

$\mathrm{Al}$ Issa and MacIan [1] classified CCFL data according to the horizontal pipe length to diameter ratio into four groups: $\left(L_{H} / D\right)=0-5,5-10,10-25$, and $>40$. Vallée et al. [3] selected experimental studies using the horizontal pipe length to diameter ratio of $\left(L_{H} / D\right)=7-10$ to compare CCFL characteristics in hot leg models. Major test conditions in previous studies are listed in Table 1. The empirical constant $C$ in (1) by Richter et al. [8] was about 0.7 , and CCFL was mitigated compared with other cases where $C$ was about 0.6 , because the horizontal pipe length to diameter ratio $\left(L_{H} / D\right)$ was small.

Figure 1 compares the CCFL data listed in Table 1. The solid line in Figure 1 was an empirical correlation obtained by fitting the data of the $1 / 15$-scale test given by [6]

$$
\left(J_{G}^{*}\right)^{1 / 2}=0.608-0.238\left(J_{L}^{*}\right)^{1 / 2}-1.28\left(J_{L}^{*}\right) .
$$

In the UPTF tests (Mayinger et al. [9]), the diameter of the hot leg was $D=0.75 \mathrm{~m}$, and the hydraulic diameter in the region with the ECC (emergency core cooling) injection tube was $D_{h}=0.65 \mathrm{~m}$. As can be seen in Figure 1, there 


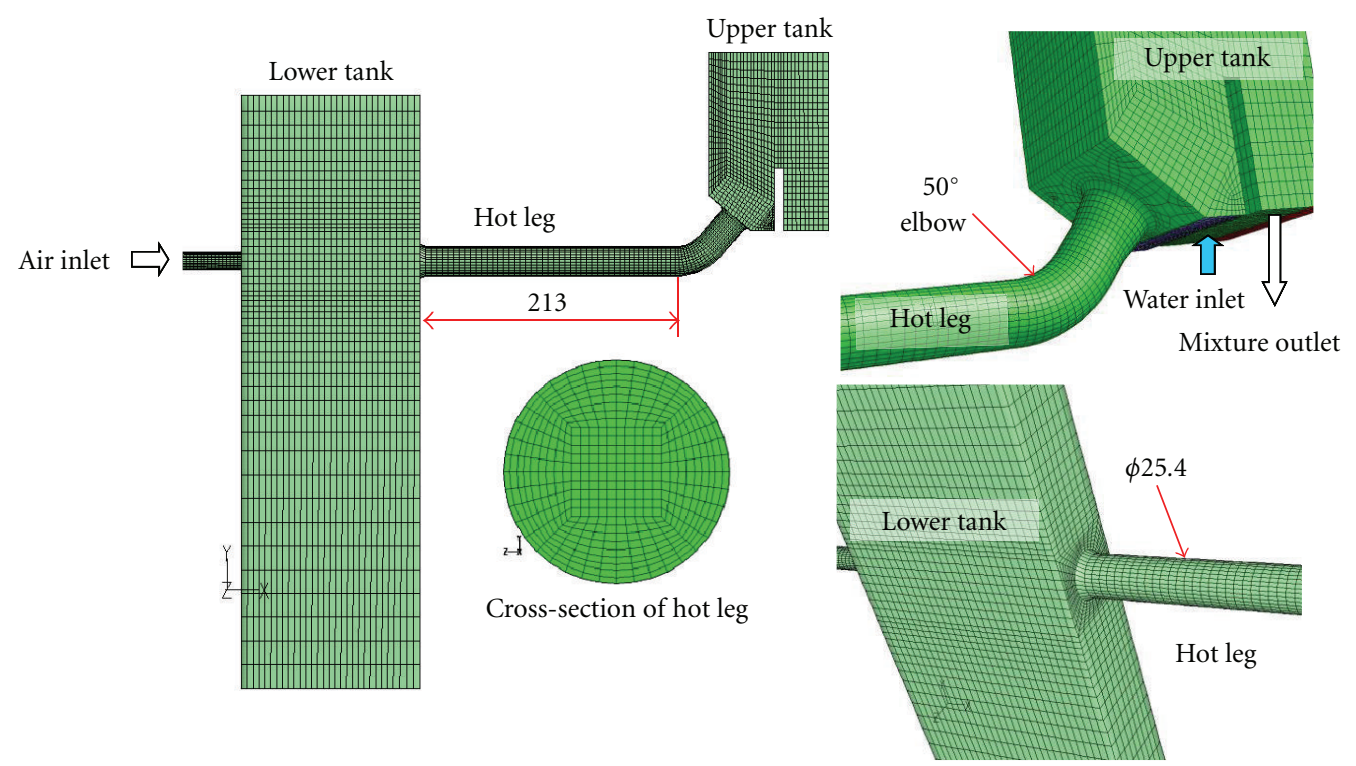

Figure 2: Computational grids (unit: $\mathrm{mm}$ ).

were no significant differences between CCFL characteristics obtained under conditions of $0.05 \mathrm{~m} \leq D \leq 0.75 \mathrm{~m}$. However, the empirical constant $C$ by Ohnuki et al. [7] was about 0.55 , and CCFL became severer compared with other cases. The objective of this study was to evaluate the reason why CCFL for $D=0.0254 \mathrm{~m}$ became severer.

\section{Simulation Method}

In the numerical simulations, the two-fluid model and the standard $k-\varepsilon$ turbulence model implemented in FLUENT6.3.26 were used. Conservation equations for momentum, volume fraction, turbulent kinetic energy, and turbulent dissipation rate of the gas and liquid phases were solved using the first-order upwind scheme, because calculations with the second-order upwind scheme became unstable. The phase-coupled-SIMPLE method was used for the pressurevelocity coupling.

3.1. Computational Grid. Figure 2 shows the computational grid for the air-water tests with the $D=0.0254 \mathrm{~m} \mathrm{[7],} \mathrm{which}$ was reduced from the computational grid for a full-scale PWR hot leg [6]. Because velocity distributions of gas and liquid at both ends of the hot leg affect hydraulic behavior, the calculation region included the lower tank simulating the upper plenum in the reactor vessel and the upper tank simulating the SG inlet plenum. There were 460 calculation cells in the cross-section of the hot leg and about 120,000 calculation cells in total. The diameter of the hot leg and the length of the horizontal pipe were $D=0.0254 \mathrm{~m}$ and $L_{H}=0.213 \mathrm{~m}\left(L_{H} / D=8.4\right)$. The length of the tapered section was not included in the length of the horizontal pipe (including the tapered section, $\left.L_{H} / D=8.6\right) .\left(L_{H} / D\right)$ in the computational grid was a little smaller than that $\left(L_{H} / D=9.1\right)$ in the tests conducted by Ohnuki et al. [7].
Gas was supplied from the side wall into the lower tank and flowed into the upper tank through the hot leg. Water was supplied from the bottom of the upper tank. Some water gravitationally flowed into the lower tank through the hot leg. The water flow rate through the hot leg was calculated from the increasing rate of water volume in the lower tank. The boundary condition of constant velocity was used at the inlets of gas and water, and the boundary condition of constant pressure was used at the outlet of the gas-water mixture.

3.2. Interfacial Drag Coefficient. In the two-fluid model, we implemented the interfacial drag coefficients as a user function of FLUENT. In the momentum equation, the interfacial drag force $F_{i}\left(\mathrm{~N} / \mathrm{m}^{3}\right)$ is defined by

$$
F_{i}=-\frac{1}{2} C_{D} A_{i} \rho_{G}\left|u_{r}\right| u_{r}
$$

where $u_{r}(\mathrm{~m} / \mathrm{s})$ is the relative velocity between the gas and liquid phases and $A_{i}\left(\mathrm{~m}^{2} / \mathrm{m}^{3}\right)$ is the interfacial area concentration. We used a combination of the following three correlations of the interfacial drag coefficients $\left(C_{D} A_{i}\right)$ as a function of local void fraction $\alpha$ [4]:

$$
\begin{gathered}
C_{D} A_{i}=\min \left[\left(C_{D} A_{i}\right)_{L}, \max \left\{\left(C_{D} A_{i}\right)_{M},\left(C_{D} A_{i}\right)_{H}\right\}\right], \\
\left(C_{D} A_{i}\right)_{L}=2 \alpha(1-\alpha) g / V_{g i}^{2}, \\
\left(C_{D} A_{i}\right)_{M}=9.8(1-\alpha)^{3}\left(4.5 \alpha / D_{h}\right), \\
\left(C_{D} A_{i}\right)_{H}=0.02\{1+75(1-\alpha)\} \alpha^{0.5} / D_{h},
\end{gathered}
$$

where $D_{h}(\mathrm{~m})$ is the hydraulic diameter. Equation (6) was originally proposed by Andersen [13] for one-dimensional two-phase flow, and Minato et al. [14] applied it to threedimensional calculations. Equations (7) and (8) are based 


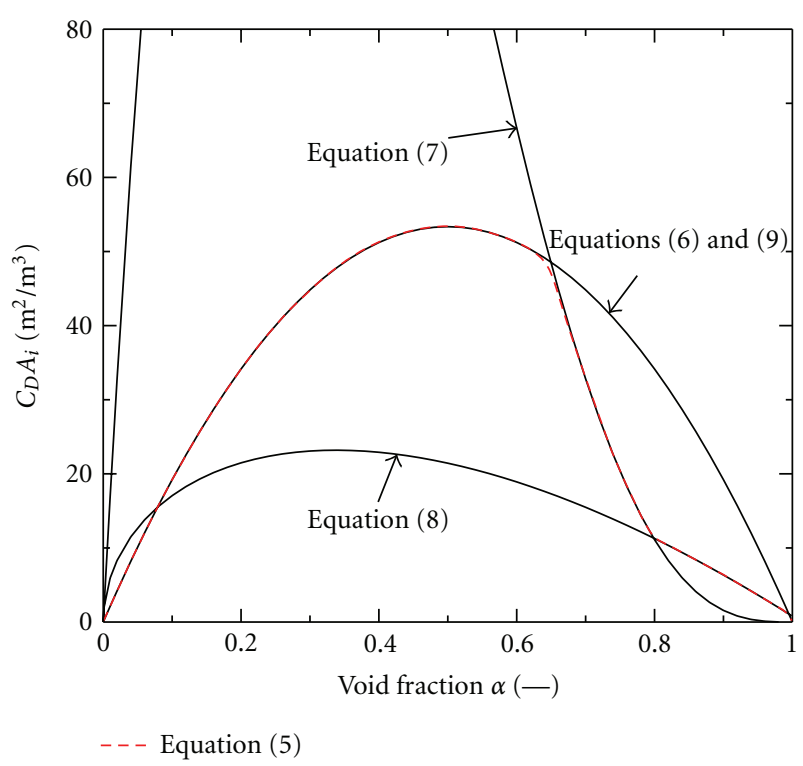

Figure 3: Interfacial drag coefficients $\left(D_{h}=0.0254 \mathrm{~m}\right)$.

on correlations for slug flow [15] and annular flow [2], respectively. Equation (7) was simplified from the original correlation by Ishii and Mishima [15] using $\alpha_{g s}=0$, where $\alpha_{g s}$ is void fraction of small bubbles. In (6), drift velocity $V_{g j}(\mathrm{~m} / \mathrm{s})$ for stagnant liquid, which was simplified from the original correlation [16], was used:

$$
\begin{gathered}
V_{g i}=1.4\left(D_{h}^{*}\right)^{0.125}\left\{\frac{g \sigma\left(\rho_{L}-\rho_{G}\right)}{\rho_{L}^{2}}\right\}^{1 / 4}, \\
D_{h}^{*}=D_{h}\left\{\frac{g\left(\rho_{L}-\rho_{G}\right)}{\sigma}\right\}^{1 / 2},
\end{gathered}
$$

where $\sigma(\mathrm{N} / \mathrm{m})$ is the surface tension.

The combination of (5) through (9) was verified by numerical simulations [4-6] for the 1/5-scale rectangular channel tests and the 1/15-scale circular channel tests conducted at Kobe University and the full-scale UPTF tests [9]. The two-fluid model with the combination of (5) through (9) could reproduce CCFL characteristics under low pressure conditions. In this study, the two-fluid model with the combination of (5) through (9) and the computational grid shown in Figure 2 were used in numerical simulations conducted for the air-water tests with the diameter of $0.0254 \mathrm{~m}$. In order to evaluate the size effect, the simulated results were compared with the data [7] as well as the simulated results for $D=0.05 \mathrm{~m} \mathrm{[5]} \mathrm{and} 0.75 \mathrm{~m}$ [6], which were predicted by the same method used in this study except for size.

Figure 3 shows the interfacial drag coefficients $\left(C_{D} A_{i}\right)$ calculated using (5) through (9) for the air-water system at $0.1 \mathrm{MPa}$ with the diameter of $0.0254 \mathrm{~m}$. Equations (7) and (8) are functions of void fraction and the hydraulic diameter. These are inversely proportional to the hydraulic diameter. On the other hand, (6) is a function of void fraction and drift velocity, which depends on fluid properties as expressed by (9). However, the effect of fluid properties on (6) is not large.

\section{Results and Discussion}

4.1. Flow Patterns. Figure 4 shows predicted flow patterns for $D=0.0254 \mathrm{~m}$ compared with a flow pattern observed in the Ohunki experiments $(D=0.0254 \mathrm{~m})$ [7] versus flow patterns observed [12] and predicted [4] for the 1/15-scale air-water tests $(D=0.05 \mathrm{~m})$. Under CCFL conditions in the Ohnuki experiments, an instable roll wave grew near the elbow in the horizontal section. Some roll waves grew up, and those waves were blown up to the upper tank by air upflow. The depth of the water layer near the agitated region was thicker than that near the lower tank. The predicted flow patterns for $D=$ $0.0254 \mathrm{~m}$ were quite similar to the observed ones. At higher $J_{G}$, a water slug fell through the inclined section, where the two flows combined and formed a roll wave near the elbow, and CCFL took place at the junction of the elbow and the horizontal section. The water flow was mainly limited at this location. Accordingly, the water depth was the highest at the junction and decreased toward the lower tank. As $J_{G}$ decreased, water depth in the horizontal section became higher, and the falling water flow rate through the hot leg became larger.

As shown in Figures 4(c) and 4(d), the above mentioned findings about flow patterns for $D=0.0254 \mathrm{~m}$ were almost the same as the observed and predicted flow patterns for the $1 / 15$-scale hot leg model $(D=0.05 \mathrm{~m})$. Thus, there was no qualitative difference between the flow patterns for $D=0.0254 \mathrm{~m}$ and $D=0.05 \mathrm{~m}$.

4.2. CCFL Characteristics. Figure 5 shows the predicted CCFL characteristics for $D=0.0254 \mathrm{~m}$ compared with the CCFL data measured by Ohnuki et al. [7]. The zero liquid penetration limits (i.e., CCFL constants $C$ of the Wallis correlation, (2)) agreed very well with each other. On the other hand, the numerical simulation slightly underestimated the slope $m$ of the CCFL correlation compared with the measured data [7]. This may be due to the difference of $\left(L_{H} / D\right)$ between the two hot leg models.

Figure 5 also shows the CCFL characteristics predicted by the two-fluid model for the 1/15-scale hot leg model [5] as well as a full-scale hot leg model [6]. The geometric characteristics of these hot leg models are summarized in Table 2. As can be seen in Figure 5, the CCFL characteristics were well correlated with the Wallis parameters for $0.05 \mathrm{~m} \leq$ $D \leq 0.75 \mathrm{~m}$, and the best-fit CCFL correlation was expressed by (3). However, the present predicted CCFL characteristics for $D=0.0254 \mathrm{~m}$ were severer compared with those for $0.05 \mathrm{~m} \leq D \leq 0.75 \mathrm{~m}$, which were predicted by the same calculation model and method except for size. It follows from these results that the measured CCFL difference between $D=0.0254 \mathrm{~m}$ and $0.05 \mathrm{~m} \leq D \leq 0.75 \mathrm{~m}$ was caused by the size effect and not by other factors.

4.3. Discussion. In the experiments, there are many differences such as specification and characteristics of the test facility and test section, test methods and conditions, and measurements and data evaluation methods, which may affect CCFL characteristics. Therefore, it is very important to 


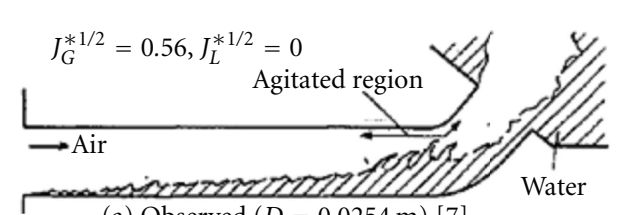

(a) Observed $(D=0.0254 \mathrm{~m})[7]$

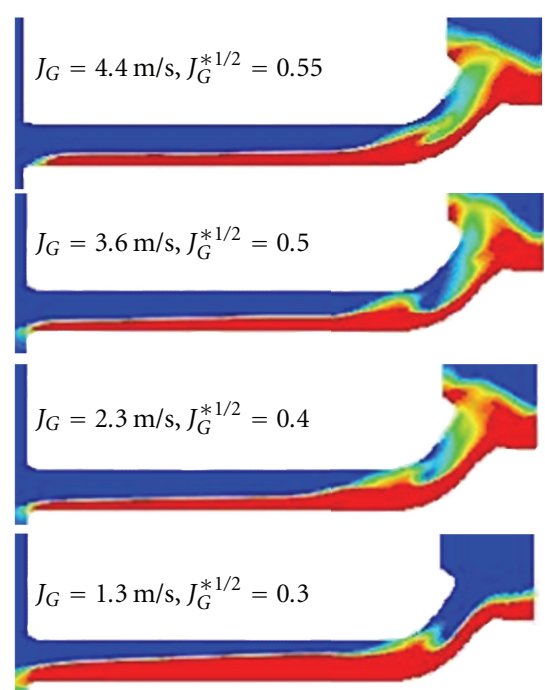

(b) Predicted $(D=0.0254 \mathrm{~m})$

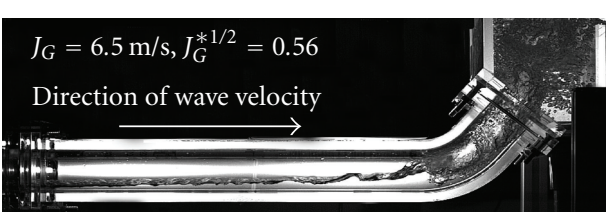

(c) Observed $(D=0.05 \mathrm{~m})[12]$

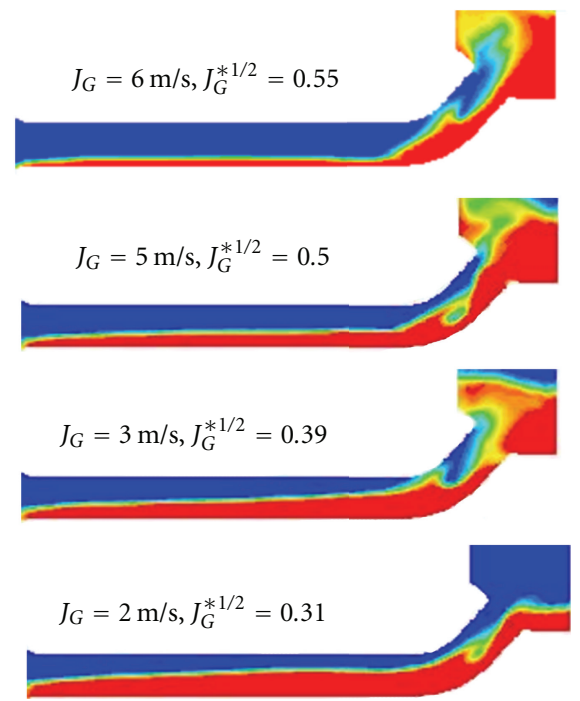

(d) Predicted $(D=0.05 \mathrm{~m})[5]$

Liquid volume fraction

\begin{tabular}{lllll}
\hline & & & & \\
\hline & 0.25 & 0.5 & 0.75 & 1
\end{tabular}

Figure 4: Predicted flow patterns.

TABLE 2: Test section dimensions and experimental and simulation conditions.

\begin{tabular}{|c|c|c|c|c|c|c|}
\hline Reference & $D(\mathrm{~m})$ & $L_{H} / D(-)$ & $L_{I} / D(-)$ & $\theta(\operatorname{deg})$ & Fluids & Pressure $(\mathrm{MPa})$ \\
\hline \multicolumn{7}{|l|}{ Experiments } \\
\hline Ohnuki et al. [7] & 0.0254 & 9.06 & 1.18 & 50 & Air-water & 0.1 \\
\hline \multicolumn{7}{|l|}{ Simulations } \\
\hline Present study & 0.0254 & 8.40 & 1.20 & 50 & Air-water & 0.1 \\
\hline Minami et al. [5] & 0.05 & 8.40 & 1.20 & 50 & Air-water & 0.1 \\
\hline Kinoshita et al. [6] & 0.75 & 8.40 & 1.20 & 50 & Air-water and steam-water & 0.1 \\
\hline
\end{tabular}

$D$ : diameter, $L_{H}$ : length of horizontal pipe, $L_{I}$ : length of inclined pipe, $\theta$ : angle of elbow.

reproduce the trend of test results by numerical simulations using the same calculation model and schemes to verify numerical methods and also confirm test results.

In Figure 6, the CCFL constants $C$ for hot leg models listed in Tables 1 and 2 were arranged according to diameters $D$ or hydraulic diameters $D_{h}$ of the cross-sections. For the UPTF data (Mayinger et al. [9]), the inner diameter without Hutze $(D=0.75 \mathrm{~m})$ as well as the hydraulic diameter at the location of Hutze $\left(D_{h}=0.65 \mathrm{~m}\right)$ were used as the characteristics lengths of Wallis parameters, (2). Judging from the experiments of Ohnuki et al. [7], the CCFL constant for $D=$
$0.75 \mathrm{~m}$ without Hutze was estimated to be between the UPTF data for $D=0.75 \mathrm{~m}$ and $D_{h}=0.65 \mathrm{~m}$. As shown in Figure 6, the CCFL constants of the measurements for $D_{h} \geq 0.05 \mathrm{~m}$ were almost the same and approximately 0.61 on average.

Accordingly, the CCFL constant for a real PWR hot leg $(D=0.75 \mathrm{~m})$ was estimated to be 0.61 , which agreed well with 0.608 in (3). On the contrary, for small hydraulic diameters $\left(D_{h}=0.0254 \mathrm{~m}\right)$, the CCFL constants became small (i.e., CCFL became severe). As can be seen by comparing the simulation results with measured results, the two-fluid model simulation well reproduced the CCFL 


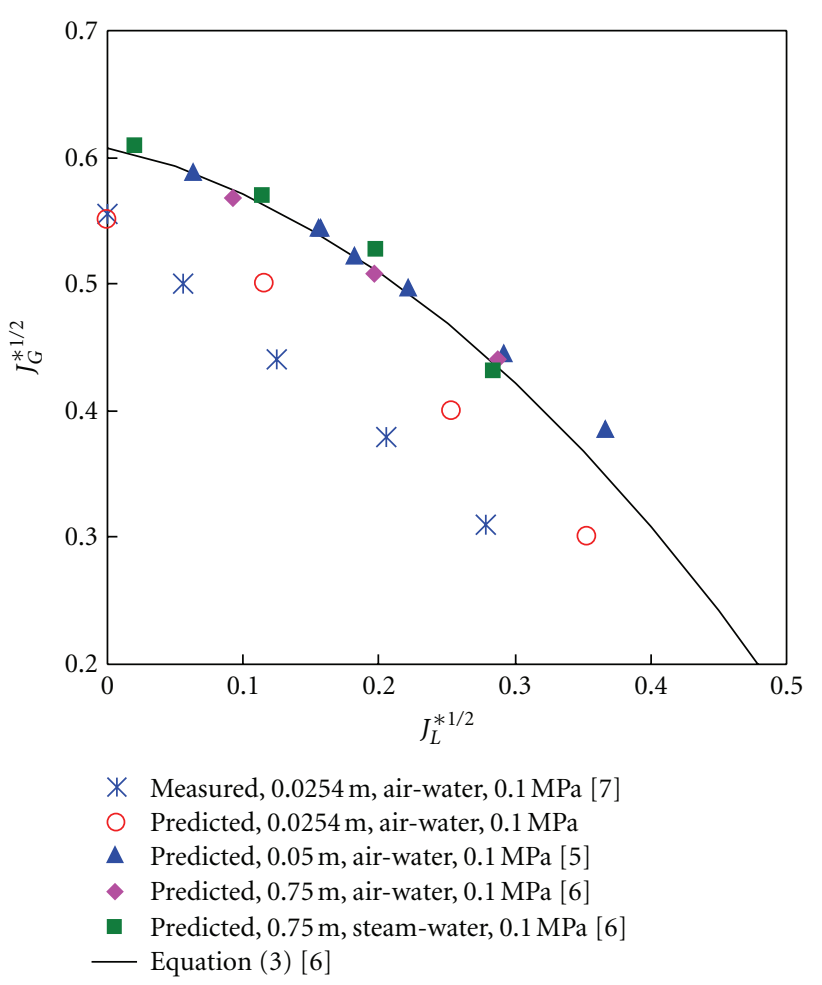

FIgURe 5: Predicted CCFL characteristics.

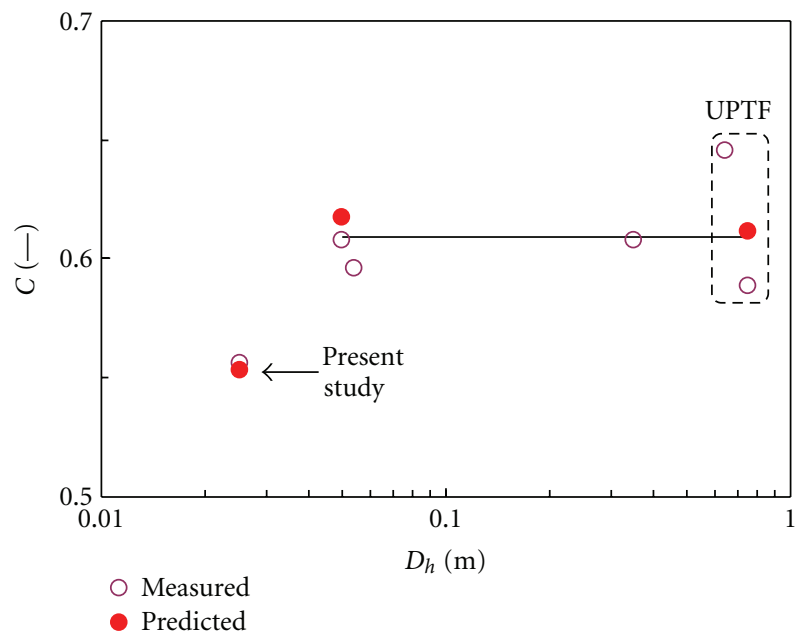

FIGURE 6: CCFL constants arranged by hydraulic diameters.

constants of hot leg models in the wide range of $D_{h}=$ $0.0254 \mathrm{~m}$ to $0.75 \mathrm{~m}$.

\section{Conclusions}

In order to evaluate whether the CCFL difference between $D=0.0254 \mathrm{~m}$ and $0.05 \mathrm{~m}$ is because of the size effect or other factors, we did numerical simulations using the twofluid model for the air-water tests $(D=0.0254 \mathrm{~m})$ conducted by Ohnuki et al.
The numerical simulations well reproduced the flow patterns observed in the air-water test $(D=0.0254 \mathrm{~m})$ and the measured discrepancy in the CCFL constants seen between $D=0.0254 \mathrm{~m}$ and $0.05 \mathrm{~m} \leq D \leq 0.75 \mathrm{~m}$. This indicated that the CCFL difference between $D=0.0254 \mathrm{~m}$ and $0.05 \mathrm{~m} \leq D \leq 0.75 \mathrm{~m}$ was caused by the size effect and not by the other factors.

\section{References}

[1] S. Al Issa and R. MacIan, "A review of CCFL phenomenon," Annals of Nuclear Energy, vol. 38, no. 9, pp. 1795-1819, 2011.

[2] G. B. Wallis, One-dimensional Two-phase Flow, McGraw Hill, New York, NY, USA, 1969.

[3] C. Vallée, T. Seidel, D. Lucas, A. Tomiyama, and M. Murase, "Comparison of counter-current flow limitation experiments performed in two different models of the hot leg of a pressurized water reactor with rectangular cross-section," Journal of Engineering for Gas Turbines and Power, vol. 133, article 052917, 2011.

[4] N. Minami, M. Murase, D. Nishiwaki, and A. Tomiyama, "Countercurrent Gas-Liquid Flow in a Rectangular Channel Simulating a PWR Hot Leg (2) Analytical Evaluation of Countercurrent Flow Limitation," Japanese Journal of Multiphase Flow, vol. 22, no. 4, pp. 413-422, 2008 (Japanese).

[5] N. Minami, M. Murase, and A. Tomiyama, "Countercurrent gas-liquid flow in a PWR hot leg under reflux cooling (II) numerical simulation of 1/15-scale air-water tests," Journal of Nuclear Science and Technology, vol. 47, no. 2, pp. 149-155, 2010.

[6] I. Kinoshita, M. Murase, Y. Utanohara, N. Minami, and A. Tomiyama, "Numerical simulation of countercurrent gasliquid flow in a PWR hot leg under reflux cooling," Journal of Nuclear Science and Technology, vol. 47, no. 10, pp. 963-972, 2010.

[7] A. Ohnuki, H. Adachi, and Y. Murao, "Scale effects on countercurrent gas-liquid flow in a horizontal tube connected to an inclined riser," Nuclear Engineering and Design, vol. 107, no. 3, pp. 283-294, 1988.

[8] H. J. Richter, G. B. Wallis, K. H. Carter, and S. L. Murphy, "Deentrainment and Countercurrent Air-water Flow in a Model PWR Hot-leg, NRC-0193-9,” U. S. Nuclear Regulatory Commission, 1978.

[9] F. Mayinger, P. Weiss, and K. Wolfert, "Two-phase flow phenomena in full-scale reactor geometry," Nuclear Engineering and Design, vol. 145, no. 1-2, pp. 47-61, 1993.

[10] G. Geffraye, P. Bazin, P. Pichon, and A. Bengaouer, "CCFL in hot legs and steam generators and its prediction with the CATHARE code," in Proceedings of the 7th International Topical Meeting on Nuclear Reactor Thermal Hydraulics (NURETH '95), pp. 815-826, Saratoga Springs, NY, USA, September 1995.

[11] M. A. Navarro, "Study of countercurrent flow limitation in a horizontal pipe connected to an inclined one," Nuclear Engineering and Design, vol. 235, no. 10-12, pp. 1139-1148, 2005.

[12] N. Minami, D. Nishiwaki, T. Nariai, A. Tomiyama, and M. Murase, "Countercurrent gas-liquid flow in a PWR hot leg under reflux cooling (I) air-water tests for 1/15-scale model of a PWR hot leg," Journal of Nuclear Science and Technology, vol. 47, no. 2, pp. 142-148, 2010. 
[13] J. G. M. Andersen, "Interfacial shear for two-fluid models," American Nuclear Society Transactions, vol. 41, pp. 669-671, 1982.

[14] A. Minato, K. Takamori, and N. Ishida, "An extended twofluid model for interface behavior in gas-liquid two-phase flow," in Proceedings of the 8th International Conference on Nuclear Engineering (ICONE '00), Baltimore, Md, USA, 2000.

[15] M. Ishii and K. Mishima, "Two-fluid model and hydrodynamic constitutive relations," Nuclear Engineering and Design, vol. 82, no. 2-3, pp. 107-126, 1984.

[16] Y. Kataoka, H. Suzuki, and M. Murase, "Drift-flux parameters for upward gas flow in stagnant liquid," Journal of Nuclear Science and Technology, vol. 24, no. 7, pp. 580-586, 1987. 

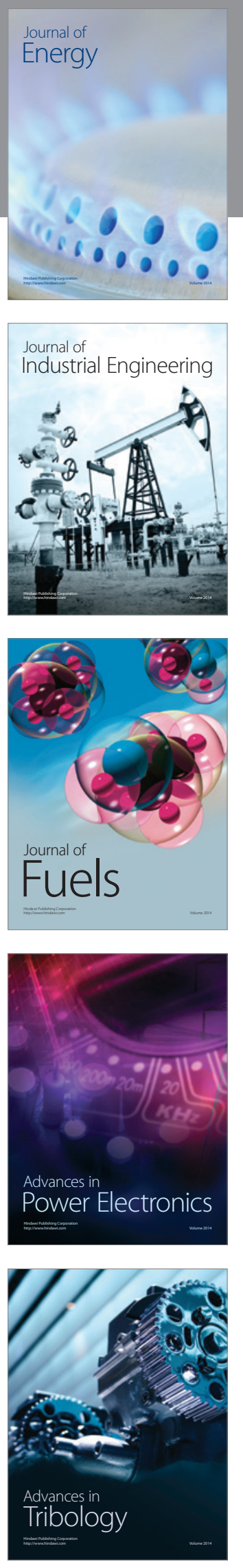
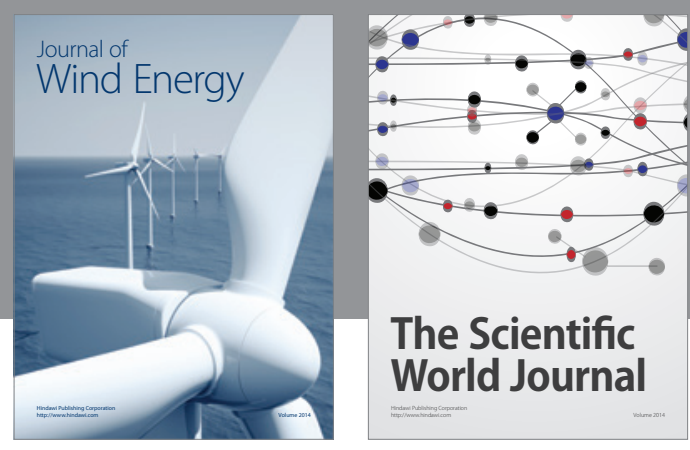

The Scientific World Journal

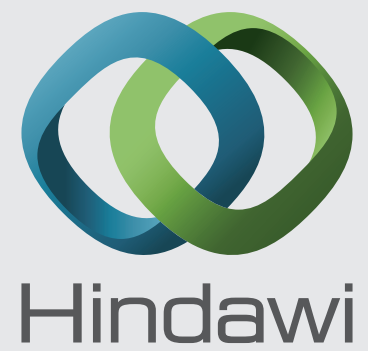

Submit your manuscripts at http://www.hindawi.com
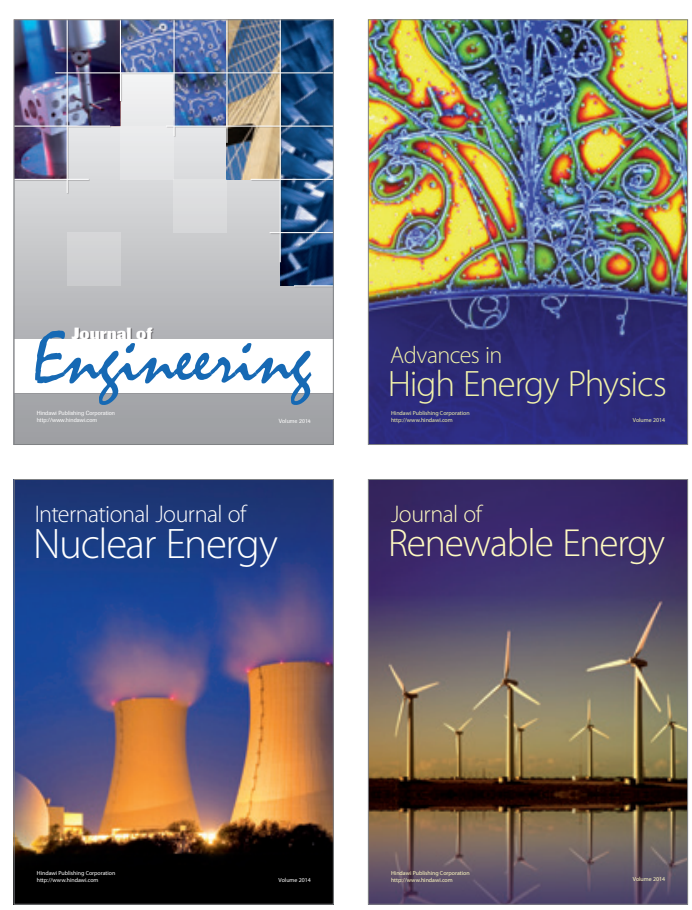

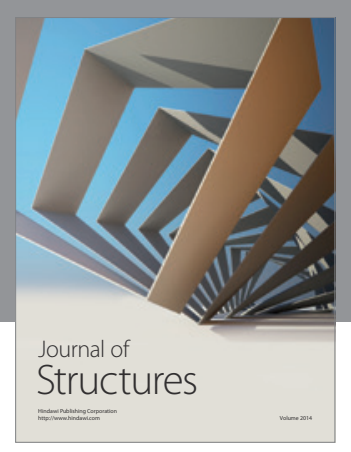

Rotating
Mechinery
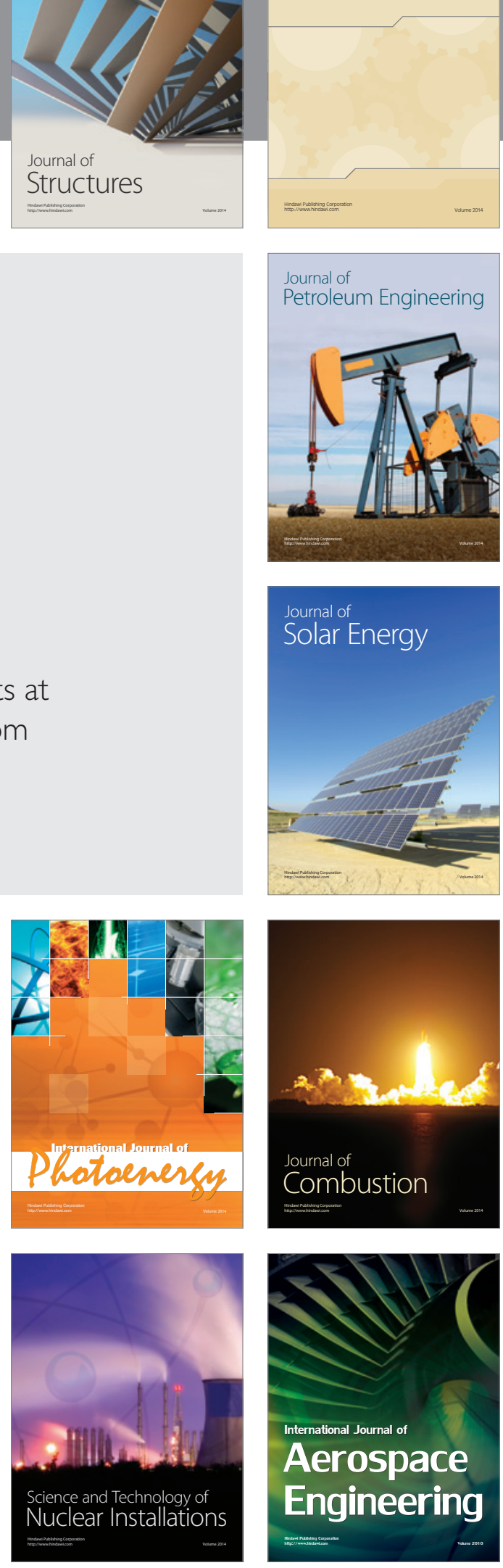